Revista Iberoamericana, Vol. LXXIII, Núm. 218, enero-marzo 2007, 313-316

\title{
LA CONTIENDA DE UNA GENERACIÓN ENTREVISTA A IGNACIO PADILLA
}

\author{
POR \\ BeRENice VillagomeZ \\ University of Toronto
}

Ignacio Padilla es uno de los mejores estilistas de su generación: su batalla con el lenguaje se extiende desde el exorcismo del barroco latinoamericano de La catedral de los ahogados (1995), a un idioma remoto que recuerda a Cervantes y Avellaneda en Si volviesen sus majestades (1996), hasta la brevedad totalizadora de Amphitryon (2000) y Espiral de artillería (2003). Sin embargo, Padilla es mejor conocido por formar parte del Crack -un grupo de amigos escritores que incluye a Jorge Volpi, Pedro Ángel Palou, Eloy Urroz, Vicente Herrasti y Ricardo Chávez-que, en 1996, intentaron distanciarse de ciertos modelos de la literatura latinoamericana que encontraban desgastados. Difícil sería medir la cantidad de tinta que se usó para demonizar inmediatamente al grupo, negando la oportunidad a sus novelas para hablar por sí mismas. No obstante, Jorge Volpi ganó el Premio Seix Barral en 1999 con En busca de Klingsor y, al año siguiente, Padilla ganó el Premio Primavera Espasa con Amphitryon. El interés que ambas novelas despertaron en Europa se trasladó a América Latina, y se concedió un espacio para que las novelas anteriores del Crack fueran consideradas. El regreso de este grupo a la escena se consolida con la reciente introducción de Revuelta: revista de pensamiento latinoamericano, publicada por la Universidad de las Américas-Puebla (de la que Pedro Ángel Palou es rector) y con varios miembros del Crack en sus páginas. Ante esta renovada presencia, la crítica ha revivido varias falsas atribuciones al fenómeno mediático que fue el Crack en la segunda mitad de los años 90. Para aclarar algunas de ellas, especialmente la falta de contienda del grupo, Ignacio Padilla y yo nos sentamos en los jardines de Hart House, en la Universidad de Toronto, una mañana de marzo.

Berenice Villagomez: Ignacio, la generación de escritores a la que perteneces no estuvo involucrada directamente en los movimientos sociales alrededor de la matanza de Tlatelolco en 1968 y muchos críticos los acusan de no tener un compromiso social. ¿Qué opinión tienes al respecto?

Ignacio Padilla: Yo nací dos meses después de la matanza de Tlatelolco, y uno imaginaría que ni a mí, ni a la mayoría de los miembros de mi generación que nacimos después de este acontecimiento, nos perjudicó. En realidad, mi familia fue directamente afectada: mi padre trabajaba en la fábrica de cartuchos de la Remington, en Cuernavaca, y ésta fue cerrada de inmediato después del 2 de octubre. Eso transformó de manera radical las condiciones económicas de mi familia y provocó nuestra migración a la ciudad de 
México, pero también alteró al país en que crecí: un país silenciado de una manera brutal. Más tarde, la represión feroz de todos los movimientos guerrilleros que vinieron en los años 70 (como el de Lucio Cabañas) y por otro lado la migración de todos los chilenos que fueron a vivir a México después del golpe de estado del 11 de septiembre de 1973, influyeron la manera en que fue educada la clase media de la Ciudad de México -a la que pertenezco, sin duda alguna. Además, haber vivido y crecido en la ciudad más grande del mundo es también una marca definitiva: vivir en un país subdesarrollado pero en una ciudad que se desarrolla caóticamente causó un profundo impacto en mi formación.

BV: En medio de una circunstancia social tan hostil, ¿qué te orilló a ser escritor?

IP: Creo que tengo la ventaja de siempre haber querido escribir. Escribo desde que recuerdo que leo; por eso siempre defiendo como algo fundamental para forjar a un escritor o a un lector la relación entre la paternidad y la literatura. Si no fuera por la constante narración del mundo y el imaginario que hacía mi madre para mí y mis hermanos cuando éramos pequeños, estoy seguro de que no me hubiera sentido inclinado a la literatura. $\mathrm{Y}$ aunque mis hermanos no son escritores, son buenos lectores que saben entender, respetar y disfrutar la literatura. Me tocó, además, la fortuna de vivir en una casa donde la profesión literaria y la labor del escritor eran más admirada que despreciada. Siempre tuve el incentivo en casa de dedicarme a escribir: desde muy pequeño empecé a escribir novelas -no cuentos ni poemas- que, por supuesto, nunca pasaron del primer capítulo. Pero siempre he tenido la certeza, la bendición y la maldición de saber que no puedo ser otra cosa que escritor. Aún cuando quisiera no escribir, no podría dejar de hacerlo.

BV: A pesar de la influencia de los hechos históricos en las décadas tempranas de tu formación y una decidida vocación literaria, tú mismo afirmaste en el Manifiesto Crack que uno de los pocos elementos que unifica a tu generación es la ausencia de contienda. Pero lo que tú proponías como una condición positiva hacia una literatura sin definiciones, ha sido transformado por la crítica en un rasgo negativo definitorio del grupo del Crack. A casi diez años del Manifiesto, ¿̇aún crees que son un grupo sin contienda?

IP: Durante mucho tiempo los miembros de mi generación y los miembros del Crack estuvimos convencidos de la falta de contienda, porque generalmente ésta aparece en la adolescencia de los escritores o en la primera juventud. Nosotros no sospechábamos que nuestra contienda estaba por venir, y el acontecimiento histórico que nos marca como escritores mexicanos en México es el terremoto de 1985, que no sólo fue un fenómeno natural sino que es un planteamiento social y político radical en la historia del país. El acontecimiento mundial que nos interpela y nos dice que la historia también tenía deparado algo para nosotros fue la caída del muro de Berlín en el 89. De pronto, descubrimos que la mayor contienda del escritor de nuestra generación es encontrar, replantear, la alternativa a la supuesta facción triunfante de la Guerra Fría. Yo creo que es un reto y una contienda incluso más grave y comprometedora que la que habían vivido nuestros antecesores que tuvieron que decidir entre la izquierda y la derecha radicales. Nosotros tenemos una contienda infinitamente más difícil, que es decir: "Señores, los que triunfaron no son los buenos de la película porque también son fundamentalistas y redencionistas”. Y nos toca la última gran contienda que es el 11 de septiembre de 2001. Nadie en su sano juicio, con una conciencia y una función hacia la palabra, los medios y 
la intelectualidad puede mantenerse indiferente ante lo que está planteando el 11 de septiembre como un reto histórico.

BV: Hay que descubrir quién está debajo de la máscara. Comienzas tu sección del Manifiesto hablando de Pessoa, y el epígrafe de Amphitryon también es una cita suya, como una clave de la disociación e impostura que permea tus relatos. ¿Consideras que la contienda que ahora mencionas se introduce -quizás de manera inconsciente- en las reflexiones sobre la identidad y sobre la maldad que son temas constantes en tus obras?

IP: La reflexión sobre la maldad es una obsesión que se alimenta e intercambia por mi relación con otros amigos escritores. Con ellos comparto mi formación: clase media mexicana, en el seno de familias de provincia, educados en escuelas católicas que inevitablemente te conducen a meditar sobre esos temas. Nuestra reflexión sobre el mal no es en el sentido del malditismo, sino un poco metafísica. Nos preguntamos fríamente ¿qué es el mal? ¿cuál es el origen del mal? ¿ existe o no el mal? Yo he llevado el agua hacia el molino de la consideración sobre el infierno y el diablo; Jorge Volpi concentra su interés sobre el mal exclusivamente humano y el saber, en una reflexión más faústica. En cuanto a la identidad, yo creo que es bastante lógico que cualquiera con un pie en esta tierra el día de hoy tiene que preguntarse cuál es la situación de la identidad y por qué fue así en nuestro brutal, atroz y brevísimo siglo xx que empezó y terminó en los Balcanes con una confrontación sobre el problema de la identidad religiosa, nacional y lingüística no sólo de Europa, sino del mundo entero.

BV: Quizás considerando esta última preocupación de tu generación, la crítica ha señalado repetidas veces que la literatura del Crack no se preocupa por México, sino que escribe sobre Europa. ¿Tú crees que esa es una característica definitoria de tu grupo?

IP: No, definitivamente no. Es un mito provocado por el impacto mediático de dos novelas que son En busca de Klingsor y Amphytrion, aunque sí hay otras dos novelas que ocurren fuera de México, como Diorama de Vicente Herrasti y Malheridos de Pedro Ángel Palou. Sin embargo, en realidad la mayoría de las novelas y cuentos escritos por autores del Crack ocurren en México, y es muy probable que siga siendo así. Nosotros admiramos profundamente a la generación de Casa del Lago, Carlos Fuentes y Octavio Paz, los Contemporáneos y Alfonso Reyes, porque son los representantes de una visión despreocupadamente universal del mundo. Vemos con absoluta naturalidad un libro como Farabeuf de Salvador Elizondo, de la misma manera en que vemos con profunda admiración un libro que habla de México tanto como La región más transparente de Carlos Fuentes. No hay ni nacionalismo forzado ni cosmopolitismo forzado. La literatura se ve como una sola cosa; México se concibe como parte de un todo y la universalidad de toda esa tradición de la literatura latinoamericana es una de las líneas que nos parece de las más respetables y dignas de ser aprendidas por la nueva literatura.

En mi caso particular, he procurado -quizás por razones psicológicas o estéticas- no situar mis novelas, no tanto por eludir México sino para evitar que sean ubicadas en cualquier lugar del mundo. Amphytrion es una excepción a la regla, así como Las antípodas y el siglo son también cuentos excepcionales en mi trayectoria, que procura desubicar sus historias. Creo que el efecto de extrañeza es parte del fenómeno literario que provoca la experiencia catártica. Yo no he abordado la guerra de los Balcanes o el problema de la identidad en el siglo xx de una manera extremadamente consciente, como 
una consecuencia de mis inquietudes como individuo, sino por mis inquietudes literarias. Sin embargo, cuando uno escribe algo no sabe con exactitud lo que resultará y lo averigua después de haberlo escrito. Luego que terminé Amphytrion descubrí que hay una reflexión sobre el mal en el siglo xx, de la misma manera en que después de escribir Las antípodas y el siglo encontré una reflexión sobre el viaje y la confrontación cultural de la globalización. De igual forma, escribí Espiral de artillería que, para mí, era una novela de submarinos y termina siendo una reflexión sobre la situación caótica y claustrofóbica de la transición de los países ex-soviéticos al liberalismo de hoy en día. A pesar de que esta novela ocurre aparentemente en un cementerio submarino del mar de Bering es, en general, una reflexión sobre las transiciones que incluyen a América Latina. Estoy seguro de que los peruanos en este momento están desconcertados con el gobierno de Toledo, y los venezolanos -que finalmente, pusieron a Chávez donde está- tienen dudas serias sobre la democracia misma. En Rusia, el día de hoy, la transición ha sido dolorosa y si bien se ha escrito mucho sobre la caída del régimen, yo creo que ya es hora de que se escriba sobre el dolor del cambio y la transición. Esta novela habla sobre eso: sobre mi cambio y mi desencanto con el cambio de México que no llega, que si antes se perdonaba por inexperiencia, ahora no se perdona por necedad. Habla, entonces, sobre la decepción del cambio de mucha gente tanto en Moscú como en la Ciudad de México el día de hoy.

Pero, además, el derecho de la literatura no limita al escritor, por su nacionalidad, a abordar cualquier realidad en otro lugar del mundo distinto a su país de origen. Finalmente, habitamos en un universo cada vez más vinculado, en el cual lo que ocurre al otro lado del planeta puede afectarnos de manera directa. Yo defiendo fundamentalmente el derecho del escritor a situar su historia donde sienta que ésta será mejor contada. 